\title{
Elevated temperatures increase growth and enhance foraging performances of a marine gastropod
}

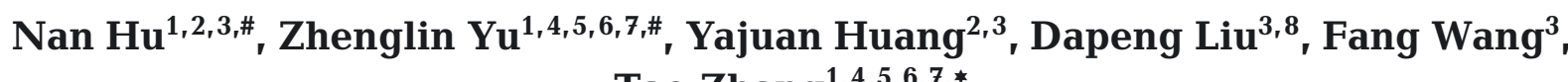 \\ Tao Zhang ${ }^{1,4,5,6,7, *}$ \\ ${ }^{1}$ CAS Key Laboratory of Marine Ecology and Environmental Sciences, Institute of Oceanology, \\ Chinese Academy of Sciences, Qingdao 266071, Shandong, PR China \\ ${ }^{2}$ Aquatic Ecology, Department of Biology, Lund University, Lund 221 00, Sweden \\ ${ }^{3}$ The Key Laboratory of Mariculture, Ministry of Education, Ocean University of China, Qingdao 266003, \\ Shandong, PR China \\ ${ }^{4}$ Laboratory for Marine Ecology and Environmental Science, Qingdao Pilot \\ National Laboratory for Marine Science and Technology, Qingdao 266237, PR China \\ ${ }^{5}$ Center for Ocean Mega-Science, Chinese Academy of Sciences, Qingdao 266071, PR China \\ ${ }^{6}$ CAS Engineering Laboratory for Marine Ranching, Institute of Oceanology, Chinese Academy of Sciences, \\ Qingdao 266071, PR China \\ ${ }^{7}$ Shandong Province Key Laboratory of Experimental Marine Biology, Qingdao 266071, PR China \\ ${ }^{8}$ School of Biology, Georgia Institute of Technology, 310 Ferst Drive, Atlanta, Georgia 30332-0230, USA
}

\begin{abstract}
The oceans continue to warm due to rising atmospheric greenhouse gas concentrations. Most climate-change studies of aquaculture species use temperature changes based on coarseresolution climate models and without considering thermal ranges of an animal. Coarse-resolution climate models are generated by global-scale data, which is insufficient to capture the conditions of coastal areas where most aquaculture activity occurs. Therefore, ocean warming research on coastal organisms requires a more comprehensive design to include broad temperature gradients. By using the ecologically and commercially important coastal whelk Rapana venosa, we combined long-term and short-term experiments and selected 4 temperature treatments $(19,23,27$, and $30^{\circ} \mathrm{C}$ ) to simulate different scenarios to test ocean warming effects on growth rates and foraging performances of whelks. We found that elevated temperature within the whelk's thermal range $\left(23\right.$ and $\left.27^{\circ} \mathrm{C}\right)$ significantly increased growth rates and enhanced foraging performances of marine whelks when compared to the current temperature $\left(19^{\circ} \mathrm{C}\right)$. Conversely, the whelk's performance collapsed at $30^{\circ} \mathrm{C}$ in terms of both growth and foraging behavior. Our research clearly shows that local conditions and the tolerance range of a species must be considered to develop meaningful information for testing the effects of a changing climate. Our study suggests that rapa whelks may increase their feeding and reach larger sizes during warmer periods. Moreover, our study may provide a foundation for future climate research on aquaculture species.
\end{abstract}

KEY WORDS: Ocean warming $\cdot$ Growth rate $\cdot$ Foraging performance $\cdot$ Predator-prey interactions $\cdot$ Rapana venosa $\cdot \mathrm{RCP} 8.5$

\section{INTRODUCTION}

As our climate continues to warm due to rising atmospheric greenhouse gas concentrations, the ocean is currently facing a variety of perturbations which include ocean warming, ocean acidification, decreased oxygen concentrations, reduced sea-ice area and rising sea levels (Hoegh-Guldberg \& Bruno 2010, Keeling et al. 2010, Doney et al. 2012, Poloczanska et al. 2013). These perturbations may 
pose a variety of threats to marine ecosystems, and affect aquaculture production (Merino et al. 2012, Handisyde et al. 2017, Barange et al. 2018, Soto et al. 2019). Studying the vulnerabilities of these systems to climate change may contribute to mitigating the negative influences, and in turn, increase aquaculture productivity.

The aquaculture industry has been growing rapidly and plays an important role in food production, providing up to $46.8 \%$ of the world's total production (including wild capture and aquaculture), of which $35.9 \%$ is marine aquaculture (FAO 2018). However, the aquaculture sector will face climatic impacts under a 'business-as-usual' gas emission scenario (FAO 2017). As climatic changes will not be the same everywhere to every stressor (Cane et al. 1997), studying the potential effects of specific stressors in specific areas is essential (Des et al. 2020).

Water temperature is a major driving factor in aquatic species and aquaculture productivity because of its importance in physiological and chemical processes and species interactions (Zippay \& Helmuth 2012, Gestoso et al. 2016). Elevated temperature can directly increase the speed of enzymatic reactions and thereby increase metabolic rates (Pörtner \& Farrell 2008). An increment in metabolism rate can increase growth rate as organisms need to increase foraging or consume more prey to keep metabolic homeostasis (Pörtner \& Peck 2010, Manríquez et al. 2017). Therefore, foraging behavior can be crucial for individuals because they need to acquire energy to maintain their life functions and assure normal activities continue. Species can respond to ocean warming in several ways: they can move to a new habitat where temperature is within their thermal niche; they may extend their thermal niche by acclimating and/or adapting to new temperatures; they can also experience range contractions when the temperature already exceeds their range, preventing endurance (Donelson et al. 2019). It has long been known that the first response by organisms to a novel environment is mainly modifying of their behavior (Tuomainen \& Candolin 2011). The inherent behavioral plasticity also implies that it may be one of the most powerful ways for animals to adjust to rapid climate change (Wong \& Candolin 2015). Moreover, critical behaviors, including foraging behavior, predator avoidance, dispersal, and migration, are all directly affected by ocean warming (Pörtner \& Peck 2010).

Extensive climate change studies have only focused on the expected scenario by the end of this century, typically based on the representative con- centration pathway (RCP) 8.5. Under this scenario, ocean temperatures are predicted to rise by an average of $2.73 \pm 0.72^{\circ} \mathrm{C}$ (mean $\pm 1 \mathrm{SD}$ ) compared to the 1990s (Bopp et al. 2013). However, this RCP projection is strongly based on averages across large spatial and/or temporal resolutions (Falconer et al. 2020). Though it is widely useful to predict general trends and potential risks, this resolution is inadequate in capturing the complexity of coastal areas, where aquaculture is located (Falconer et al. 2020). In addition, for producers, only the environmental changes in the aquaculture farm and surrounding area would affect key aspects of production. Therefore, it is essential to evaluate conditions at the local scale, especially for coastal aquaculture species that are not able to migrate.

To demonstrate this, we conducted 2 mesocosm experiments using the coastal marine whelk Rapana venosa (Valenciennes, 1846): (1) a long-term experiment $(3 \mathrm{mo})$ to test the effects of warming on the growth rate of juvenile whelks, and (2) a short-term behavioral experiment to determine the effects of warming on the whelk's foraging performance. $R$. venosa is an economically and ecologically important coastal species that accounts for $>20 \%$ of the gastropod production in China (Yu et al. 2019). $R$. venosa is usually harvested for human consumption by SCUBA divers. It is considered a potential candidate for molluscan aquaculture, as local demand for sea products is increasing. The whelk is a dominant species in the benthic ecosystem of Laizhou Bay (Hu et al. 2016) and widely distributed on all types of bottom (Kosyan 2016). R. venosa commonly feeds on clams, mussels and oysters. This common Asian species is found in muddy-sandy sublittoral areas and is well adjusted to varying physical environmental factors since it inhabits transitional coastal systems (e.g. rock pools, lagoons) where large fluctuations in temperature and other factors, like $\mathrm{pH}$, occur naturally (Wahl et al. 2016). Its commercial and ecological significance make it a suitable organism for addressing our hypotheses.

We established comprehensive temperature gradients involving 4 scenarios $\left(19,23,27\right.$ and $\left.30^{\circ} \mathrm{C}\right)$ to test the effects of different elevated temperatures on the growth and foraging performance of $R$. venosa. We hypothesized the following: (1) $R$. venosa growth and foraging performances will increase under 23 and $27^{\circ} \mathrm{C}$ when compared to $19^{\circ} \mathrm{C}_{i}(2)$ the elevated temperature of $30^{\circ} \mathrm{C}$ is beyond the species' comfort range (sublethal) (Ban et al. 2014) and, therefore, the $30^{\circ} \mathrm{C}$ scenario will decrease the growth rate and depress foraging performances. 


\section{MATERIALS AND METHODS}

\subsection{Animal collection and maintenance}

This study was conducted at the Ecology Laboratory of the Institute of Oceanology, Chinese Academy of Sciences on Furong Island in May 2016. A total of 257 adult Rapana venosa (shell length, mean \pm SD: $55.21 \pm 3.03 \mathrm{~mm}$ ) and 432 juveniles (shell length: $22.37 \pm 2.89 \mathrm{~mm}$ ) were collected from Laizhou Bay, Bohai Sea (37 13.1' N, 119 73.0' E) by SCUBA diving and immediately transported to the laboratory. Following collection, the juvenile and adult whelks were acclimated in separate fiberglass aquaria for $2 \mathrm{wk}$. The aquaria were filled with seawater under ambient conditions (temperature: $19 \pm$ $0.5^{\circ} \mathrm{C}_{i}$ salinity: $30 \pm 1 \mathrm{ppt}$ ). The juvenile whelks were used in the long-term growth experiments and adults were used in the short-term behavioral experiments. The whelks were fed Manila clams Ruditapes philippinarum twice a week. Manila clams (shell length: $19.16 \pm 0.92 \mathrm{~mm}$ ) were collected from the coastal beach close to the site of collection of the whelks. To standardize the hunger level, the whelks were not fed for $7 \mathrm{~d}$ prior to experimentation (Garton \& Stickle 1980, Giacoletti et al. 2017). The photoperiod was set to $14 \mathrm{~h}$ light:10 $\mathrm{h}$ dark (consistent with summertime in Laizhou Bay). The seawater was changed twice a week to prevent accumulation of metabolic waste.

\subsection{Experimental design}

\subsubsection{Long-term experiments: effects of elevated} temperature on growth rate

We conducted a long-term common garden experiment in a controlled temperature laboratory maintained at $18^{\circ} \mathrm{C}$. Juvenile whelks were exposed to the following temperatures: (1) $19^{\circ} \mathrm{C}$ ambient temperature, consistent with that most often experienced in the natural environment (Harding et al. 2008); (2) a $23^{\circ} \mathrm{C}$ treatment as suggested by the coarse climate resolution model (RCP 8.5) scenario for sea surface temperature by the end of this century (IPCC 2014); (3) a $27^{\circ} \mathrm{C}$ treatment, which is the maximum temperature currently experienced by whelks (e.g. rock pool); and (4) a $30^{\circ} \mathrm{C}$ treatment that has been suggested as the sublethal temperature for $R$. venosa (Ban et al. 2014). Five juvenile whelks were randomly assigned to 1 of 16 aquaria $(40.0 \mathrm{~cm} \times 15.0 \mathrm{~cm}$ $\times 40.0 \mathrm{~cm}, 24 \mathrm{l}, 15 \mathrm{~cm}$ sand sediment). Each aquarium was randomly assigned to a temperature treatment; each treatment was replicated 4 times, with a total of 80 juveniles used in the experiment. Adjustable submersible heaters with a maximum power of $100 \mathrm{~W}$ (Trixie, Aquarium-Heizer, AH 301) were used to maintain a stable temperature in each aquarium. The heaters were raised by $1^{\circ} \mathrm{C}$ per day until the final treatment temperature was reached. At the start of the experiment, juveniles did not initially differ in shell length regardless of temperature (ANOVA, all p-values $>0.14)$. During the experiments, whelks were provided clams every other day, and the empty clam shells were removed daily. The experiment lasted 90 d, from 17 April to 16 July 2016.

\subsubsection{Short-term experiments: effects of elevated temperature on foraging behaviors}

The short-term behavioral experiment with adult rapa whelks was conducted over a period of $4 \mathrm{~d}$ in the same lab as the growth experiment. A single whelk was randomly assigned to 1 of 16 circle aquaria (radius $=50 \mathrm{~cm}$, height $=40 \mathrm{~cm} ; 314$ l) with $15 \mathrm{~cm}$ of sand sediment, and each aquarium was then assigned to a temperature treatment, with each treatment including 4 replicates. Each aquarium was heated by a single $500 \mathrm{~W}$ submersible heater (EHEIM) and supplied with aerated seawater. Prior to the elevated temperature exposure, both whelks and clams were acclimated for $24 \mathrm{~h}$ at the mean water temperature of the collection site during the study period $\left(19^{\circ} \mathrm{C}\right)$. Similar to the long-term experiment, after acclimation, the heaters were also raised by $1^{\circ} \mathrm{C}$ per day until the final treatment temperature was reached. Each $1^{\circ} \mathrm{C}$ increase in seawater temperature was reached within 30 min of adjusting the heater. Twenty clams were carefully planted just below the sediment surface with the siphon upwards and relatively evenly spaced. We took care not to disturb the surrounding sediment (Seitz et al. 2001). Clams were allowed to acclimate for $24 \mathrm{~h}$, prior to the introduction of 1 adult rapa whelk to each aquarium. All trials lasted for $4 \mathrm{~d}$.

\subsection{Data collection}

After $90 \mathrm{~d}$ in the long-term growth experiments, we measured a number of morphological variables known to be proxies of growth for gastropods (Trussell \& Nicklin 2002, Bourdeau 2011). Total shell length of each whelk to the nearest $0.01 \mathrm{~mm}$ was measured with a digital caliper. We also measured wet body weight of live whelks using a non-destruc- 
tive method, following Palmer (1990). The whelks were then euthanized and the soft body parts were removed; shell weight was measured by using an electronic analytical balance to the nearest $0.0001 \mathrm{~g}$. We calculated the soft tissue section (hereinafter designated as body mass) as wet body weight minus shell weight. We analyzed the body mass, shell mass and shell length to determine the effects of warming on the growth rate of whelks.

Behavioral data of $R$. venosa over the $4 \mathrm{~d}$ period were acquired using a video recorder (model DS2CD864-EI3, China) fixed $1 \mathrm{~m}$ above the water surface; the data were stored in the recorder (Hikvision, DS-7604 N, China) for future analysis (Hu et al. 2016). Whelk behavior was quantified continuously during the $4 \mathrm{~d}$ period for all trials. Details of the foraging behavior of $R$. venosa were assessed in a previous study (Hu et al. 2016). Briefly, $R$. venosa mostly rested on the sand or on the wall of the aquarium for all temperature treatments. Burrowing behavior only occurred in the $30^{\circ} \mathrm{C}$ treatment. The moving but not searching behavior generally involved circular routes independent of the position of the clams. Searching was considered only when a predator showed a fast-directed movement towards the prey. Physical contact between a whelk and a clam was considered an encounter. Capture was thought to occur when the clam was completely wrapped by a whelk's foot. Handling of a clam began when the whelk completely enclosed the prey and ended when the whelk rejected or ingested the clam.

The following foraging performance variables were measured: (1) encounter rate-defined as total number of encounters divided by the total searching time; (2) capture rate (the probability of capture upon encounter) - calculated as the number of captures divided by the total encounters; and (3) ingestion rate (the probability of ingestion upon capture) - calculated as the number of eaten clams divided by the total captures. In addition to these foraging performances, time budgets were also measured, including searching and handling prey. The proportions of searching and handling times were calculated as total searching time or handling time divided by the total observation time, respectively. Total searching time was identified as the total time from the beginning of the search to the encounter with a clam; total handling time was estimated as the time from the initial encounter with the clam to the end of ingestion, including attacking, manipulating, and ingesting (Hu et al. 2016). Individual prey handling time was also quantified; this was defined as the average handling time for successful ingestion. Moreover, we cal- culated the predation rate per replicate as the mean number of clams consumed by the whelk per day.

Whelks have 4 main behaviors during the foraging period: (1) Resting or stationary, (2) moving but not foraging, (3) searching and (4) handling. We measured foraging activity by counting the frequencies of transition among the 4 behavioral states. Meanwhile, we compared the foraging event transitions among temperature treatments, including resting-searching (resting to searching), moving-searching, searching-handling, and handling-searching. We used kinematic graphs to assist in behavior analysis (Nadeau et al. 2009, Sun et al. 2016).

\subsection{Statistical analysis}

All data are presented as mean \pm SD. Prior to statistical analyses, probability data were arcsine-transformed. Normality and homoscedasticity of the data were tested by Shapiro-Wilk's test and Levene's test, respectively. In the long-term growth experiment, we used ANCOVA with temperature as a fixed factor to analyze body mass and shell mass. Because individual whelks within a given aquarium are not independent replicates, each aquarium was treated as a random effect nested within temperature treatment. Due to the potential soft tissue growth-shell calcification trade-off, the body mass analysis used shell mass as a covariate. The analysis of shell mass used the length of the shell as a covariate, since the length of a whelk correlates with shell mass (Trussell \& Nicklin 2002). We used a Kruskal-Wallis test to compare shell length among temperature treatments because the shell length data did not follow a normal distribution. One-way ANOVAs, followed by post hoc Tukey's test, were used to compare predation rate, foraging behaviors, time budget, and foraging activity of $R$. venosa. For the foraging events of whelks, we used 1-way ANCOVA that treated foraging activity as the covariate and temperature as the main fixed effect. In all analyses, $\mathrm{p}<0.05$ was considered statistically significant. All statistical analyses were conducted in R software, version 3.5.2 (R Core Team 2016).

\section{RESULTS}

\subsection{Long-term juvenile growth experiment}

Elevated temperatures of 23 and $27^{\circ} \mathrm{C}$ did not cause negative effects on juvenile growth traits 
(Fig. 1). The Kruskal-Wallis test showed that temperature had significant effects on shell length (Table 1); this result was mainly due to the whelks in the $30^{\circ} \mathrm{C}$ treatment growing much less than in the other treatments (Fig. 1a). The ANCOVA showed that temperature did not significantly influence the shell mass (Table 1) when the shell length was a covariate in the analysis. However, an increased temperature of 23 and $27^{\circ} \mathrm{C}$ had slightly positive effects on shell mass growth, and $30^{\circ} \mathrm{C}$ had a significantly negative effect on shell mass growth (Fig. 1b). For the soft tissue, temperature had a significant effect (Table 1). Specifically, $23^{\circ} \mathrm{C}$ slightly increased the body mass growth, but juveniles in the $27^{\circ} \mathrm{C}$ treatment showed a slight decline (Fig. 1c). Juveniles in $30^{\circ} \mathrm{C}$ treatment almost stopped body mass growth (Fig. 1c).

\subsection{Foraging behavior, activity and predation rate of Rapana venosa}

Collectively, foraging performance and predation rate of $R$. venosa were highest at 23 or $27^{\circ} \mathrm{C}$ and

Table 1. Nested ANCOVAs (F-test) on body mass and shell mass, and KruskalWallis test (rank sum test, $\chi^{2}$ ) on shell length for Rapana venosa from 4 temperature treatments. Significant effects in bold

\begin{tabular}{|lrrrrr|}
\hline Effect & SS & MS & df & $F$ or $\chi^{2}$ & p \\
\hline $\begin{array}{l}\text { Kruskal-Wallis test on log shell length } \\
\text { Temperature }\end{array}$ & & & & & \\
Log shell mass $(Y)$ vs. log shell length $(X)$ & & & & 11.735 & $\mathbf{0 . 0 0 8}$ \\
Temperature & 0.056 & 0.019 & 3 & 2.107 & 0.107 \\
Covariate & 0.247 & 0.247 & 1 & 27.944 & $<\mathbf{0 . 0 0 1}$ \\
Temperature $\times$ Covariate & 0.080 & 0.027 & 3 & 3.019 & $\mathbf{0 . 0 3 6}$ \\
Log body mass $(Y)$ vs. log shell mass $(X)$ & & & & & \\
Temperature & 0.140 & 0.047 & 3 & 12.490 & $<\mathbf{0 . 0 0 1}$ \\
Covariate & 0.044 & 0.044 & 1 & 11.732 & $<\mathbf{0 . 0 0 1}$ \\
Temperature $\times$ Covariate & 0.007 & 0.002 & 3 & 0.628 & 0.599 \\
\hline
\end{tabular}
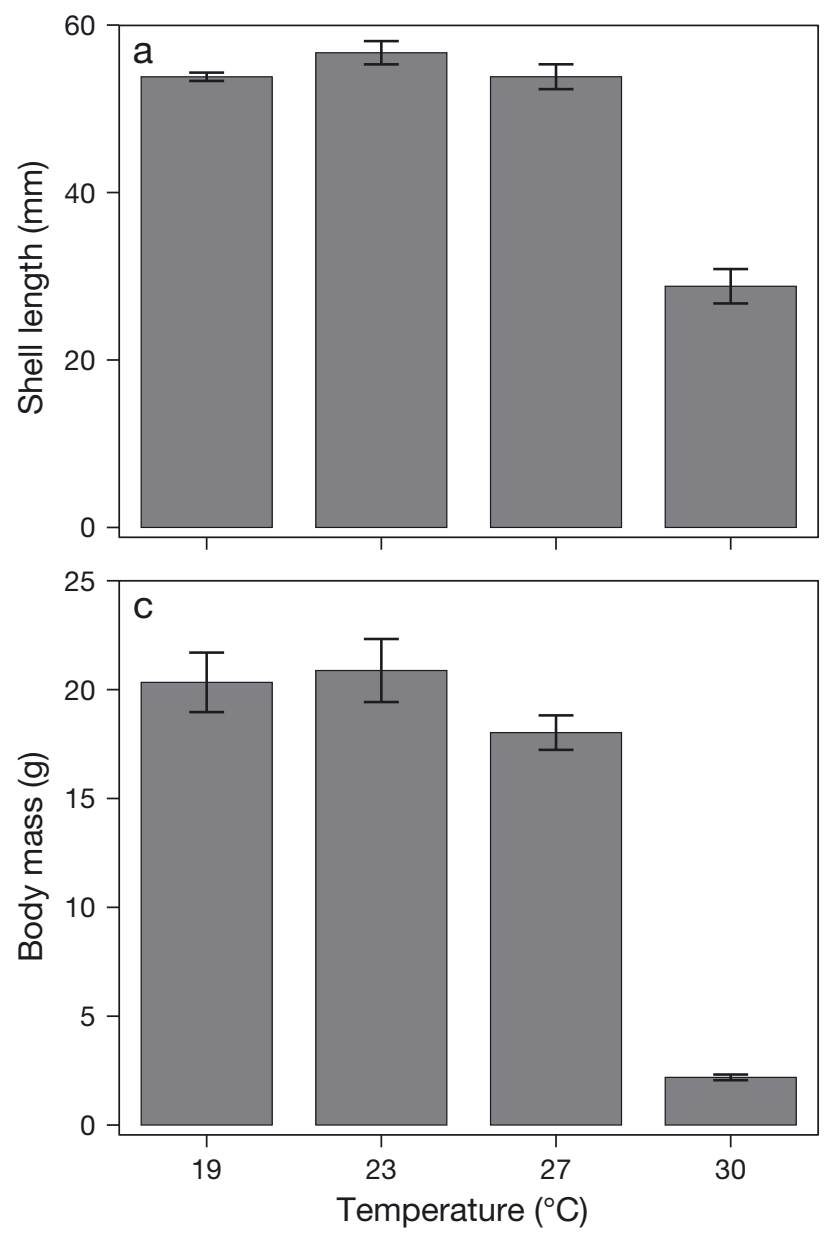

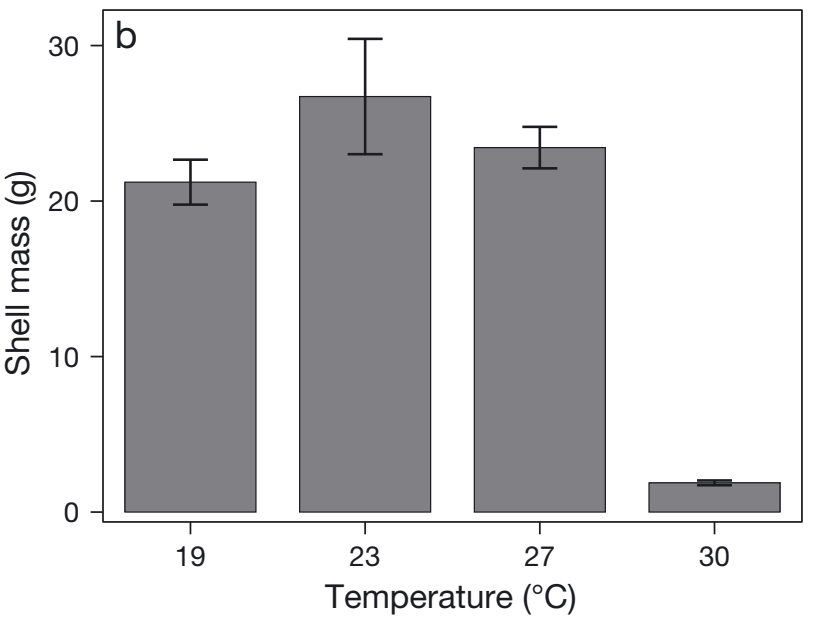

Fig. 1. Long-term effect of temperature on (a) shell length, (b) shell mass, and (c) body mass of juvenile Rapana venosa. All data are means $\pm S D, n=4$ for each temperature 
reduced significantly at $30^{\circ} \mathrm{C}$ (Fig. 2). Temperature had a significant effect on all foraging behavior and activity (Table 2). The encounter rates at 23 and $27^{\circ} \mathrm{C}$ were significantly higher than at 19 and $30^{\circ} \mathrm{C}$ (Fig. 2a). There were no significant differences between
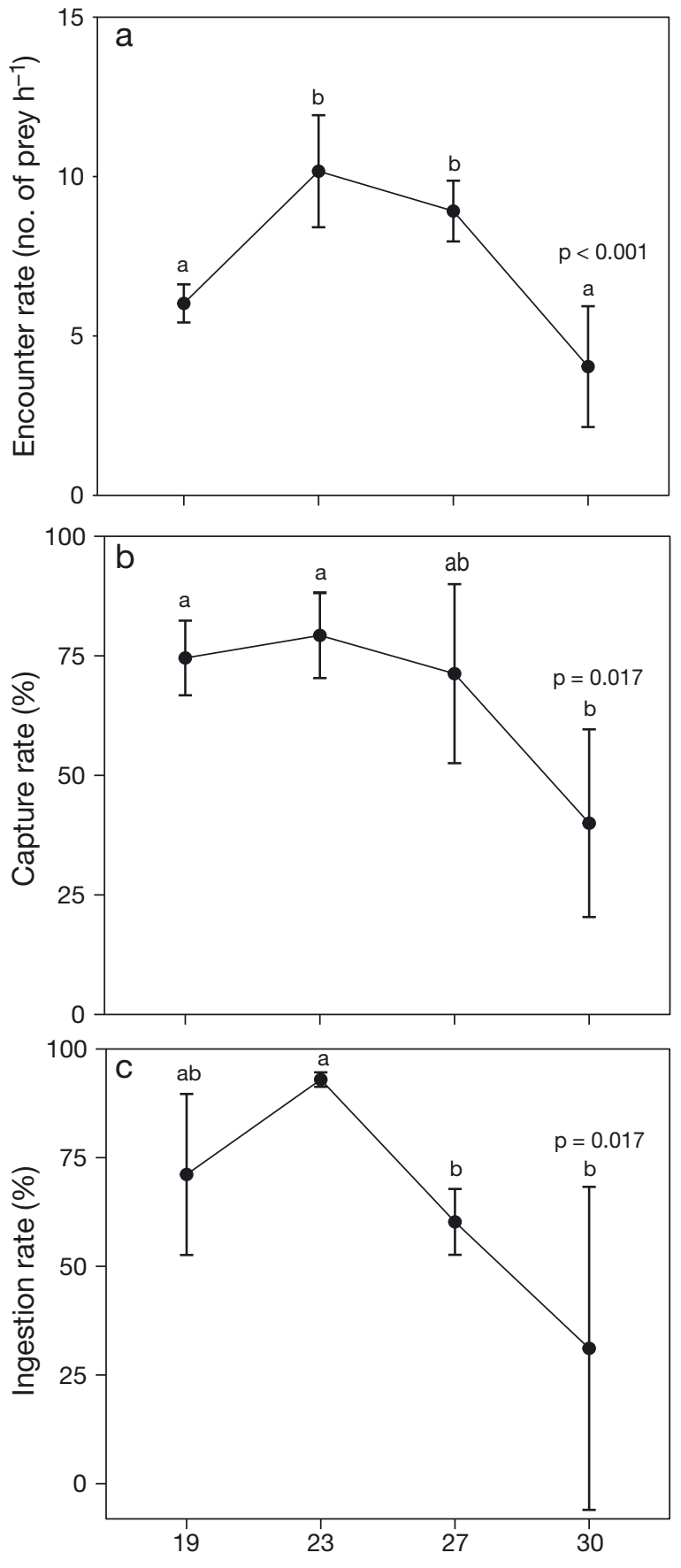

Temperature ()
23 and $27^{\circ} \mathrm{C}$ or between 19 and $30^{\circ} \mathrm{C}$ (Fig. 2a). The capture rate of $R$. venosa was significantly lower at $30^{\circ} \mathrm{C}$ than the other 3 temperatures, and there were no significant differences among the other 3 groups (Fig. 2b). Overall, the capture rate decreased with
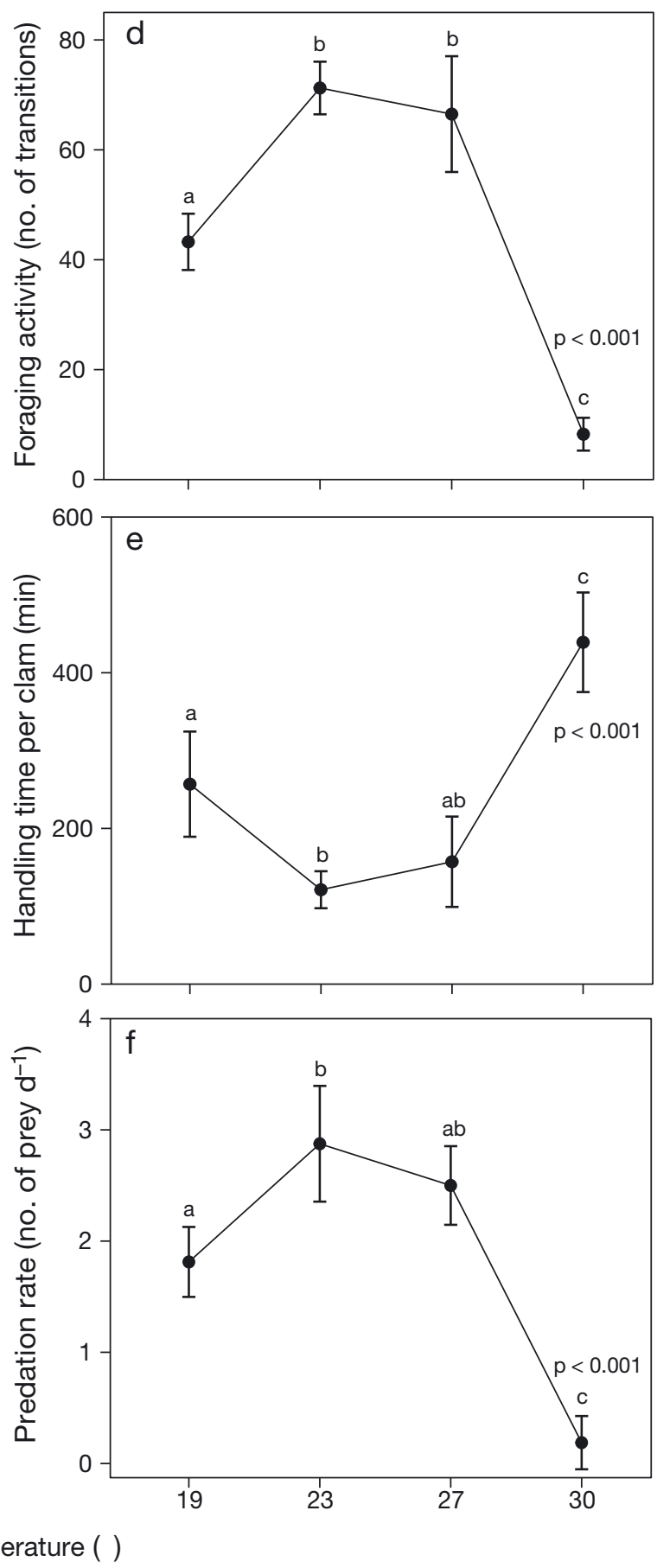

Fig. 2. Foraging performance and predation rate of adult Rapana venosa under $19,23,27$ and $30^{\circ} \mathrm{C}$ : (a) encounter rate between whelks and clams, (b) capture rate upon encounter, (c) ingestion rate upon capture, (d) foraging activity, (e) handling time per clam, and (f) predation rate. All data are means $\pm \mathrm{SD}, \mathrm{n}=4$ for each temperature. Statistical significance (p $<0.05,1$-way ANOVA) is indicated by the $\mathrm{p}$-value and different lowercase letters indicate significant differences between temperature groups 
Table 2. ANOVA for the effects of temperature on Rapana venosa foraging behaviors (encounter rate, capture rate, ingestion rate, foraging activity and handling time per clam), predation rate and time budget. Significant effects in bold

\begin{tabular}{|lcccrr|}
\hline Performance & SS & MS & df & $F$ & p \\
\hline Encounter rate & 92.481 & 30.833 & 3,12 & 15.524 & $<\mathbf{0 . 0 0 1}$ \\
Capture rate & 0.626 & 0.218 & 3,12 & 5.097 & $\mathbf{0 . 0 1 7}$ \\
Ingestion rate & 1.537 & 0.512 & 3,12 & 7.943 & $\mathbf{0 . 0 0 3}$ \\
Foraging activity & 9934.222 & 3311.435 & 3,12 & 78.342 & $<\mathbf{0 . 0 0 1}$ \\
Handling time per clam & 243383 & 81128 & 3,12 & 25.786 & $<\mathbf{0 . 0 0 1}$ \\
Predation rate & 16.952 & 5.653 & 3,12 & 40.945 & $<\mathbf{0 . 0 0 1}$ \\
Searching proportion & 0.001 & 0.0004 & 3,12 & 14.732 & $<\mathbf{0 . 0 0 1}$ \\
Handling proportion & 0.098 & 0.033 & 3,12 & 4.221 & $\mathbf{0 . 0 3 0}$ \\
\hline
\end{tabular}

increasing temperature. $R$. venosa ingested more clams at $23^{\circ} \mathrm{C}$ than at both 27 and $30^{\circ} \mathrm{C}$ (Fig. 2c). The ingestion rate at $30^{\circ} \mathrm{C}$ showed a much wider variance than the other 3 groups (Fig. 2c).

Foraging activity (transitions among 4 behaviors) significantly increased with increasing temperature but sharply decreased at $30^{\circ} \mathrm{C}$ (Figs. $2 \mathrm{~d}$ $\& 3)$. This result suggests that an elevated temperature can boost foraging activity of whelks but an extreme temperature beyond their typical thresh-

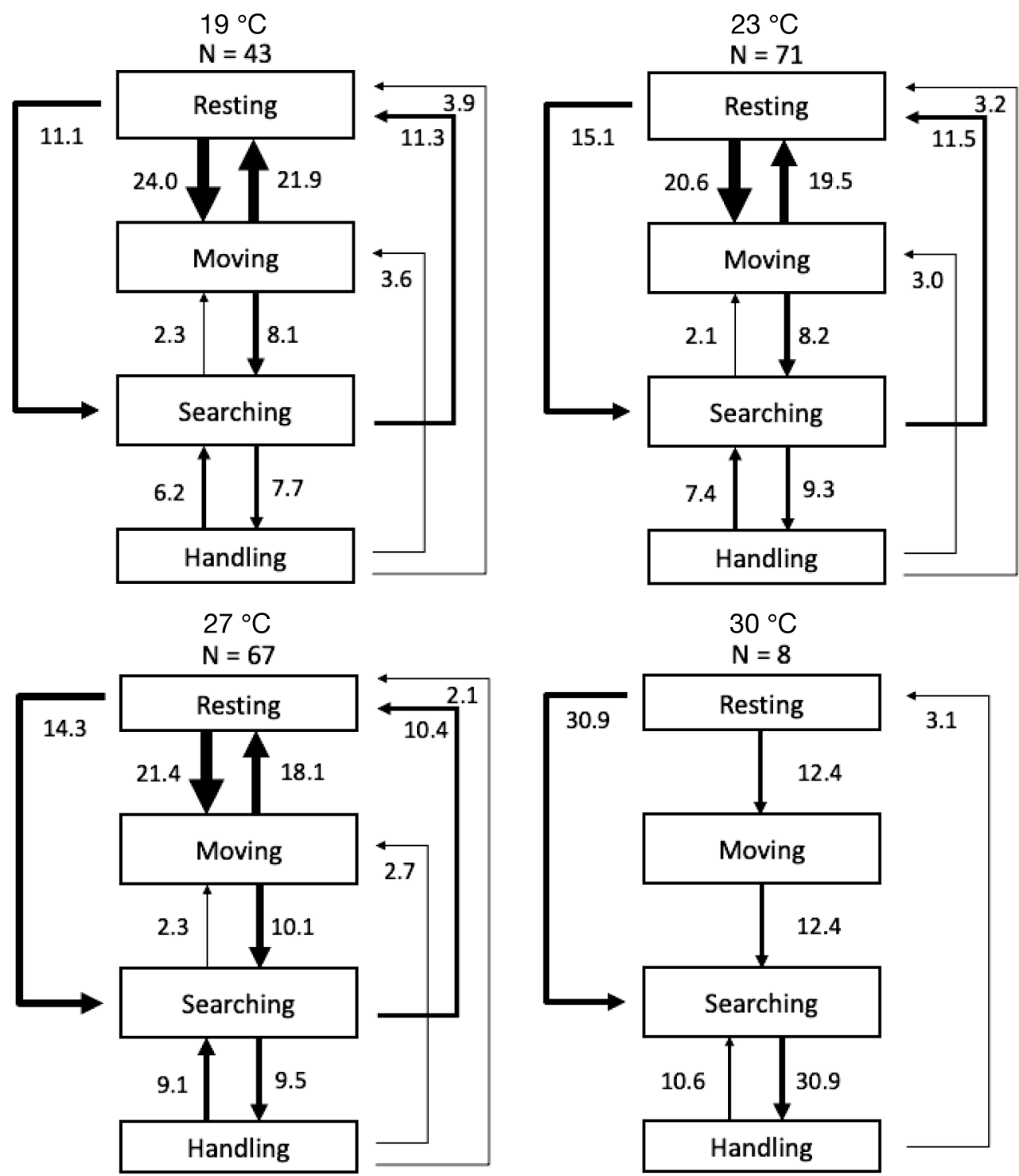

Fig. 3. Kinematic graphs of the behavioral sequences of Rapana venosa under 19, 23, 27 and $30^{\circ} \mathrm{C}$. The thickness of the arrows and the numbers beside the arrows indicate the relative frequency (\%) between 2 behaviors; $N$ : total number of transitions 
old may negatively affect foraging performance. Whelks were more active at 23 and $27^{\circ} \mathrm{C}$ than at 19 or $30^{\circ} \mathrm{C}$. It is worth noting that activity at $19^{\circ} \mathrm{C}$ was significantly greater than at $30^{\circ} \mathrm{C}$ (Fig. 2d). Handling times per clam were highest at $30^{\circ} \mathrm{C}$ when compared with the other 3 groups (Fig. 2e). Whelks at $23^{\circ} \mathrm{C}$ took relatively less time to deal with a captured prey than whelks at 19, 23, and $30^{\circ} \mathrm{C}$ (Fig. 2e). Accordingly, predation rate increased with the temperature increase from 19 to $23^{\circ} \mathrm{C}$, and sharply decreased at $30^{\circ} \mathrm{C}$ (Fig. 2f). The predation rate at $30^{\circ} \mathrm{C}$ was significantly lower than the other 3 temperatures.

Ethograms showed that the main transitions of whelks at 19,23 , and $27^{\circ} \mathrm{C}$ were between resting and non-foraging displacement, which accounted for $35.9-40.1 \%$ of the transition behavior (Fig. 3). However, the main transitions at $30^{\circ} \mathrm{C}$ were from resting to searching and searching to handling, which accounted for $>60 \%$ (Fig. 3). The ANCOVA for the effects of temperature on searching events showed that temperature had a significant effect on the

Table 3. ANCOVA for the effects of temperature, foraging activity $(X)$ and their interactive effects on Rapana venosa searching events $(Y)$. Significant effects in bold

\begin{tabular}{|lcccrc|}
\hline Foraging Performance & SS & MS & df & $F$ & p \\
\hline Searching events $(Y)$ vs. foraging activity $(X)$ & & & & \\
Temperature & 50.121 & 16.712 & 3 & 23.391 & $<\mathbf{0 . 0 0 1}$ \\
Covariate & 1251.362 & 1251.36 & 1 & 1751.892 & $<\mathbf{0 . 0 0 1}$ \\
Covariate $\times$ Temperature & 0.813 & 0.581 & 3 & 0.812 & 0.521 \\
\hline
\end{tabular}

searching events of whelks (Table 3). Also, there was a significant relationship between foraging activity and searching events as the $\mathrm{p}$-value of the covariate was significantly less than 0.001 (Table 3 ).

\subsection{Foraging time budget of $R$. venosa}

Elevated temperature had significant effects on the foraging time budget of whelks for both searching and handling (Fig. 4, Table 2). The time that whelks spent on searching was significantly less at $30^{\circ} \mathrm{C}$ than at 19, 23, and $27^{\circ} \mathrm{C}$ (Fig. 4a), which accounted for $<1 \%$ of the total observation time. Whelks spent the most time on searching at $27^{\circ} \mathrm{C}$, which was significantly greater than the time spent searching at $23^{\circ} \mathrm{C}$ but not at $19^{\circ} \mathrm{C}$ (Fig. 4a). Handling time decreased with increasing temperature (Fig. 4b). Whelks spent $35.5 \%$ of their time on handling at $19^{\circ} \mathrm{C}$, which was significantly greater than at $30^{\circ} \mathrm{C}(14.6 \%)$. However, elevated temperature within the whelk's temperature threshold $\left(23\right.$ and $27^{\circ} \mathrm{C}$ ) did not significantly affect the handling time budget, because there were no significant differences among the 19, 23, and $27^{\circ} \mathrm{C}$ groups (Fig. $4 \mathrm{~b}$ ).

\section{DISCUSSION}

Understanding and predicting the consequences of climate change in
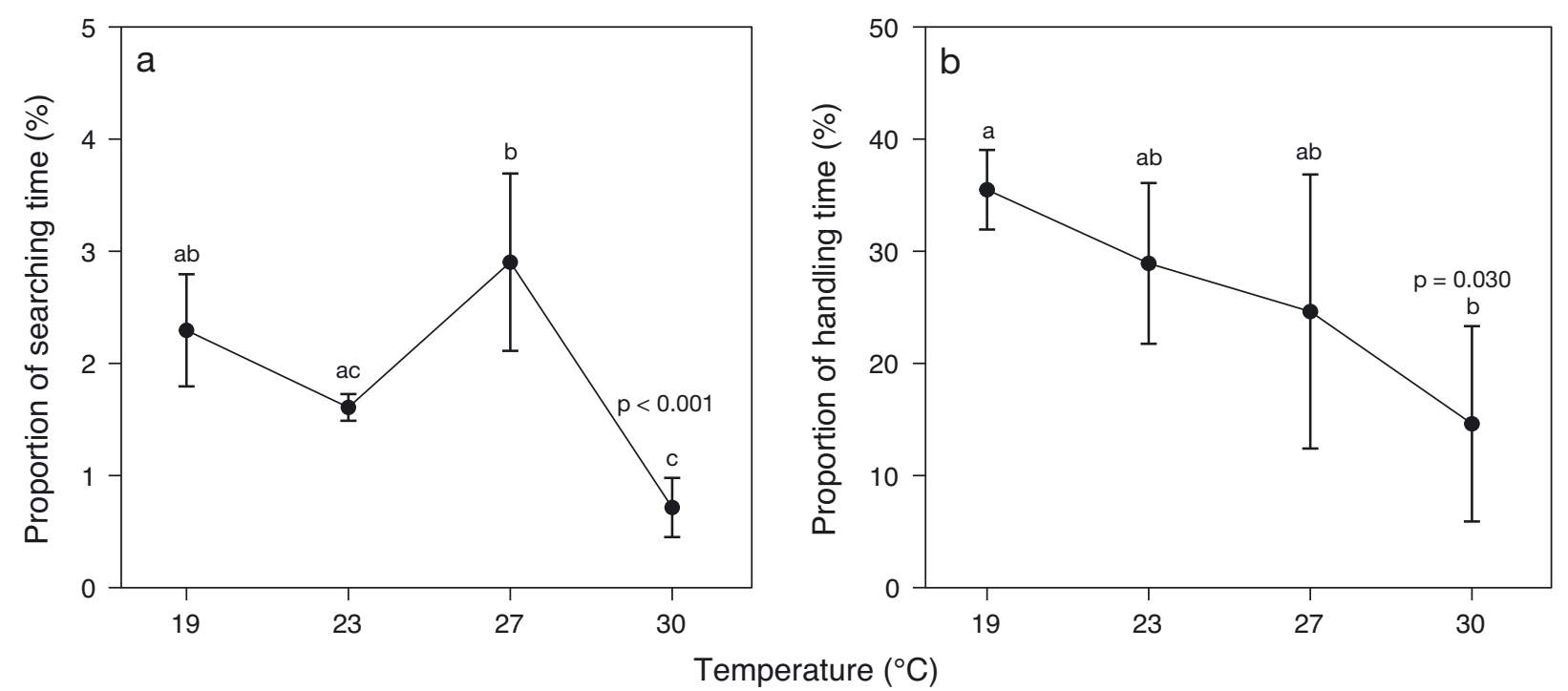

Fig. 4. Proportion of time that Rapana venosa spent on (a) searching and (b) handling under 19, 23, 27 and $30^{\circ} \mathrm{C}$. All data are means $\pm \mathrm{SD}, \mathrm{n}=4$ for each temperature. Statistical significance $(\mathrm{p}<0.05,1$-way ANOVA) is indicated by the $\mathrm{p}$-value and different lowercase letters indicate significant differences between temperature groups. Note the different $y$-axis scales 
the aquaculture industry requires properly assessing animal foraging performances and growth that directly contribute to productivity. In the current study, we jointly conducted a long-term common garden experiment and a short-term behavioral experiment to examine the effects of different warming scenarios on growth rate and foraging performance of a coastal whelk. We found that an elevated temperature of 23 and $27^{\circ} \mathrm{C}$ had positive effects on growth rate and foraging behavior, but a high temperature of $30^{\circ} \mathrm{C}$ had significantly negative effects. We also found that the optimal thermal range might broaden or increase with increased body size because the elevated temperatures had a greater positive effect on adults than on juveniles.

\subsection{Effects of elevated temperature on juvenile growth}

Our findings show similarities but also differences from previous studies on the effects of ocean warming on marine organism growth. In our study, an elevated temperature of 23 and $27^{\circ} \mathrm{C}$ did not have negative effects on growth; instead, we detected a slight positive effect. Several studies have identified significantly negative effects of ocean warming (Hoffman et al. 2003, Reynaud et al. 2003, Metzger et al. 2007). The lack of a similar negative result in Rapana venosa could be explained by the relative thermal tolerances of $R$. venosa when compared to other marine species. $R$. venosa performed best between $19 \sim 27^{\circ} \mathrm{C}$, suggesting these temperatures are within its thermal range. This finding is consistent with a previous study on rapa whelks (Song et al. 2016). In the $30^{\circ} \mathrm{C}$ treatment, whelks sealed themselves off by borrowing into the substrate and ceased most activities. The whelks maintained at $30^{\circ} \mathrm{C}$ grew less than in the other treatments. Such findings suggest the thermal limits of this species should be between 27 and $30^{\circ} \mathrm{C}$. Yang et al. (2019) found rapa whelks had little to no food intake at $28^{\circ} \mathrm{C}$. Similarly, Harding et al. (2008) showed that temperatures below $28^{\circ} \mathrm{C}$ could promote reproduction in rapa whelks. Growth and reproduction are fitness-related life-history traits that determine the population sustaining itself. Therefore, the combination of our study and previous research suggests we may reasonably accept that the upper thermal limit of rapa whelks in Laizhou Bay is $28^{\circ} \mathrm{C}$. Moreover, our findings show that $R$. venosa growth rates are not likely to be affected or increased under future oceanic warming throughout much of the species' range.

\subsection{Effects of ocean warming on adult foraging performances}

In our study, elevated temperatures within the current limits (23 and $27^{\circ} \mathrm{C}$ ) enhanced foraging performance when compared to the present-day average temperature $\left(19^{\circ} \mathrm{C}\right)$. Specifically, encounter rate, capture rate, ingestion rate, and foraging activity were all boosted by an elevated temperature, with whelks consuming more clams. Also, the time taken to open the clamshell (handling time per prey) decreased, which is consistent with the rising foraging performance; this may be due to 2 factors. Firstly, it may be explained by increased metabolic rates with temperature (Biro et al. 2007, Pörtner \& Farrell 2008). Elevated temperatures can increase metabolic rates in animals, and therefore, animals need to forage more and feed on more prey to produce the additional energy to offset the greater metabolic costs in order to maintain normal performance (Jobling 1997, Biro et al. 2007, Nagelkerken \& Munday 2016). Secondly, prey performance including avoidance behavior and anti-predator ability can also play a crucial role in shaping predator behavior (Freitas et al. 2007, Allan et al. 2015). The burrowing rate of clams was greatly increased from 23 to $27^{\circ} \mathrm{C}$. Consequently, the searching time for whelks was significantly increased at $27^{\circ} \mathrm{C}$ when compared to $23^{\circ} \mathrm{C}$, suggesting that this was likely to be a crucial factor in the whelks' foraging performance. Similarly, the elevated temperature linearly reduced the anti-predator endurance of clams, resulting in a lower proportion of the whelk's time spent handling in increased temperatures.

However, if temperatures fall outside of the optimal range, performance usually declines (Brett 1971, 1979, Jobling 1997). This was demonstrated again in our study, as all foraging performances, including predation rate, sharply decreased at $30^{\circ} \mathrm{C}$. Additionally, regardless of the physiological mechanisms, decline in foraging performance and activity might be short-term protective strategies for $R$. venosa against extreme ocean warming. Although these strategies can bring temporary mitigation from a stressor (Guppy \& Withers 1999), they are considered non-adaptive in the longer term. Long-term inactive foraging may lead to lower energetic intake than required, leading to deleterious metabolic trade-offs such as reduced growth or reproduction, or even death (Munday et al. 2012). However, although temperatures within the current limits $\left(23\right.$ and $27^{\circ} \mathrm{C}$ ) seemed to enhance foraging activity of $R$. venosa, greater foraging activity may lead to greater vulnerability to predators (Biro et al. 2007). For instance, 
Biro et al. (2007) found that an elevated temperature increased the feeding activity of the young rainbow trout Oncorhynchus mykiss but reduced survival to only half due to predation. Given that $R$. venosa shares the same prey (e.g. bivalves, barnacles, and gastropods) with crabs, which are also a typical predator of whelks, it is likely that greater foraging activity of the whelk would surely increase the risk of predation by crabs.

\subsection{Implications for whelk aquaculture}

Aquaculture now produces more sea product than wild-capture fisheries (Waite et al. 2014, FAO 2016), and has immense potential to sustainably support the continuously growing human population (Gentry et al. 2017, Hambrey 2017). However, coarse-resolution climate models based on global or regional averages are insufficient to capture the conditions of coastal areas where most aquaculture activity is located (Falconer et al. 2020). The thermal fluctuations along coastal areas are substantial (Elisio et al. 2020), and therefore, most coastal organisms already experience temperature variations. Consequently, directly using the coarse-resolution climate models may underestimate the effects of climate change on aquaculture organisms. In our study, thermal regimes on $R$. venosa have been observed to vary by up to $4-8^{\circ} \mathrm{C}$ on a diurnal cycle during summer months (pers. obs.). The results showed that elevated temperatures based on the coarse climate resolution model (RCP 8.5) were within the previously experienced range $\left(23\right.$ and $\left.27^{\circ} \mathrm{C}\right)$. This temperature range clearly increased the growth rate, enhanced foraging performance and thus increased the feeding rate. This obviously underestimates the effects of climate change because it tested the effects of whelks' optimum temperatures instead of climate change. When whelks were exposed to $30^{\circ} \mathrm{C}$, growth rate was suppressed and foraging performance and consumption collapsed. Therefore, the culturing of this species should avoid extremely high temperatures. Our study suggests that local conditions and the actual thermal range experienced by a species must be considered when studying climate change effects on species in coastal areas.

Our study suggests that whelks may increase their feeding rate and reach larger sizes in warmer environments. The finding suggests that shallower areas may be a more productive zone for the farming activity of rapa whelks because the shallower areas can rarely reach $27^{\circ} \mathrm{C}$ for the whole year in Laizhou Bay.
However, previous studies found that elevated temperature might affect the shell thickness and strength of mollusks, with higher temperatures resulting in thinner and frailer shells (Lagos et al. 2016, Martinez et al. 2018). The changes in the shells of mollusks may increase their vulnerability to predators and parasites (e.g. perforating polychaetes), and increase the risks of shell breakage and mortality during capture and transportation in the commercial process. Therefore, the shell characteristics of whelks under different temperature scenarios should be a key focus for future research. In addition, the growth rate of $R$. venosa may depend on life stage, as a previous study found that the optimal temperature for the culture of rapa whelk larvae ranged from 28 to $31^{\circ} \mathrm{C}$ (Zhang et al. 2017). This temperature is beyond the comfort range of adult whelks. Thus, the farmer should consider temperature requirement variations when producing whelks.

\section{CONCLUSIONS}

We found that an elevated temperature that was within the species' thermal range had positive effects on growth rate and foraging performance of a marine gastropod. Such findings have demonstrated here that responses to anthropogenic ocean warming will not always be negative. This is a particularly important consideration when predicting taxon-specific responses to global warming. We have also demonstrated that coastal areas with large climatic fluctuations should be fully considered when studying coastal species. Furthermore, species-specific responses may have serious ecological and practical consequences when interacting organisms show different responses to the same stress. Our study provides insight into the practical culture of the economically and ecologically important whelk Rapana venosa.

Acknowledgements. This study was supported by the National Natural Science Foundation of China (Grant number 32002374), the National Natural Science Foundation of China (Grant number 31972814 and Grant number 32002409), the Natural Science Foundation of Shandong Province (grant no. ZR2019BD003), the China Postdoctoral Science Foundation (grant no. 2019M652498), Major Scientific and Technological Innovation Project of Shandong Provincial Key Research and Development Program (2019JZZY020708), the Earmarked Fund for Modern Agroindustry Technology Research System (CARS-49), the Industry Leading Talents Project of Taishan Scholars (recipient: T.Z.), the 'Double Hundred' Blue Industry Leader Team of Yantai (recipient: T.Z.), the National Natural Science Foundation of China (grant no. 31572636), and the Creative 
Team Project of the Laboratory for Marine Ecology and Environmental Science, Qingdao National Laboratory for Marine Science and Technology (no. LMEES-CTSP-2018-1). The funders had no role in the study design, data collection and analysis, decision to publish or preparation of the manuscript. All applicable international, national, and institutional guidelines for the care and use of animals were followed.

\section{LITERATURE CITED}

Allan BJM, Domenici P, Munday PL, McCormick MI (2015) Feeling the heat: the effect of acute temperature changes on predator-prey interactions in coral reef fish. Conserv Physiol 3:cov011

Ban S, Zhang T, Pan H, Pan Y, Wang P, Xue D (2014) Effects of temperature and salinity on the development of embryos and larvae of the veined rapa whelk Rapana venosa (Valenciennes, 1846). Chin J Oceanol Limnol 32: 773-782

Barange M, Bahri T, Beveridge MCM, Cochrane KL, Funge Smith S, Poulain F (2018) Impacts of climate change on fisheries and aquaculture: synthesis of current knowledge, adaptation and mitigation options. FAO Fish Aquacult Tech Pap 627

Biro PA, Post JR, Booth DJ (2007) Mechanisms for climateinduced mortality of fish populations in whole-lake experiments. Proc Natl Acad Sci USA 104:9715-9719

Bopp L, Resplandy L, Orr JC, Doney SC and others (2013) Multiple stressors of ocean ecosystems in the 21 st century: projections with CMIP5 models. Biogeosciences 10: 6225-6245

Bourdeau PE (2011) Constitutive and inducible defensive traits in co-occurring marine snails distributed across a vertical rocky intertidal gradient. Funct Ecol 25:177-185

Brett JR (1971) Energetic responses of salmon to temperature. A study of some thermal relations in the physiology and freshwater ecology of sockeye salmon (Oncorhynchus nerka). Am Zool 11:99-113

Brett JR (1979) Environmental factors and growth. In: Hoar WS, Randall DJ, Brett JR (eds) Fish physiology, Vol VIII: bioenergetics and growth. Academic Press, New York, NY, p 599-677

Cane MA, Clement AC, Kaplan A, Kushnir Y and others (1997) Twentieth-century sea surface temperature trends. Science 275:957-960

* Des M, Gómez-Gesteira M, deCastro M, Gómez-Gesteira L, Sousa MC (2020) How can ocean warming at the NW Iberian Peninsula affect mussel aquaculture? Sci Total Environ 709:136117

* Donelson JM, Sunday JM, Figueira WF, Gaitán-Espitia JD and others (2019) Understanding interactions between plasticity, adaptation and range shifts in response to marine environmental change. Philos Trans R Soc B 374: 20180186

*Doney SC, Ruckelshaus M, Emmett Duffy J, Barry JP and others (2012) Climate change impacts on marine ecosystems. Annu Rev Mar Sci 4:11-37

* Elisio M, Maenza RA, Luz Clara M, Baldoni AG (2020) Modeling the bottom temperature variation patterns on a coastal marine ecosystem of the Southwestern Atlantic Ocean (El Rincón), with special emphasis on thermal changes affecting fish populations. J Mar Syst 212: 103445
Falconer L, Hjøllo SS, Telfer TC, McAdam BJ, Hermansen $\varnothing$, Ytteborg E (2020) The importance of calibrating climate change projections to local conditions at aquaculture sites. Aquaculture 514:734487

FAO (2016) The state of world fisheries and aquaculture 2016 (SOFIA). FAO, Rome

FAO (2017) Adaptation strategies of the aquaculture sector to the impacts of climate change. FAO Fish Aquacult Circ 1142

FAO (2018) The state of world fisheries and aquaculture 2018: meeting the sustainable development goals. FAO, Rome

Freitas V, Campos J, Fonds M, Van der Veer HW (2007) Potential impact of temperature change on epibenthic predator-bivalve prey interactions in temperate estuaries. J Therm Biol 32:328-340

Garton D, Stickle WB (1980) Effects of salinity and temperature on the predation rate of Thais haemastoma on Crassostrea virginica spat. Biol Bull 158:49-57

* Gentry RR, Froehlich HE, Grimm D, Kareiva P and others (2017) Mapping the global potential for marine aquaculture. Nat Ecol Evol 1:1317-1324

*Gestoso I, Arenas F, Olabarria C (2016) Ecological interactions modulate responses of two intertidal mussel species to changes in temperature and $\mathrm{pH}$. J Exp Mar Biol Ecol 474:116-125

*Giacoletti A, Maricchiolo G, Mirto S, Genovese L, Umani M, Sarà G (2017) Functional and energetic consequences of climate change on a predatory whelk. Estuar Coast Shelf Sci 189:66-73

*Guppy M, Withers P (1999) Metabolic depression in animals: physiological perspectives and biochemical generalizations. Biol Rev Camb Philos Soc 74:1-40

Hambrey J (2017) The 2030 agenda and the sustainable development goals: the challenge for aquaculture development and management. FAO Fish Aquacult Circ 1141

* Handisyde N, Telfer TC, Ross LG (2017) Vulnerability of aquaculture-related livelihoods to changing climate at the global scale. Fish Fish 18:466-488

* Harding JM, Mann R, Kilduff CW (2008) Influence of environmental factors and female size on reproductive output in an invasive temperate marine gastropod Rapana venosa (Muricidae). Mar Biol 155:571-581

*Hoegh-Guldberg O, Bruno JF (2010) The impact of climate change on the world's marine ecosystems. Science 328: 1523-1528

* Hoffman JR, Hansen LJ, Klinger T (2003) Interactions between UV radiation and temperature limit inferences from single-factor experiments. J Phycol 39:268-272

* Hu N, Wang F, Zhang T, Song H, Yu ZL, Liu DP (2016) Prey selection and foraging behavior of the whelk Rapana venosa. Mar Biol 163:233

IPCC (2014) Climate change 2014: synthesis report. Core Writing Team, Pachauri RK, Meyer LA (eds) Contribution of Working Groups I, II and III to the Fifth Assessment Report of the Intergovernmental Panel on Climate Change. IPCC, Geneva

Jobling M (1997) Temperature and growth: modulation of growth rate via temperature change. In: Wood CM, McDonald DG (eds) Global warming: implications for freshwater and marine fish. Semin Ser Soc Exp Biol, Vol 61. Cambridge University Press, Cambridge, p 225-254

Keeling RF, Körtzinger A, Gruber N (2010) Ocean deoxygenation in a warming world. Annu Rev Mar Sci 2: $199-229$ 
Kosyan A (2016) Predation mechanisms of Rapana venosa (Gastropoda: Muricidae) in different biotopes along the Black Sea coast. Mar Pollut Bull 102:265-270

Lagos NA, Benítez S, Duarte C, Lardies MA and others (2016) Effects of temperature and ocean acidification on shell characteristics of Argopecten purpuratus: implications for scallop aquaculture in an upwelling-influenced area. Aquacult Environ Interact 8:357-370

Manríquez PH, Torres R, Matson PG, Lee MR and others (2017) Effects of ocean warming and acidification on the early benthic ontogeny of an ecologically and economically important echinoderm. Mar Ecol Prog Ser 563: 169-184

* Martinez M, Mangano MC, Maricchiolo G, Genovese L, Mazzola A, Sarà G (2018) Measuring the effects of temperature rise on Mediterranean shellfish aquaculture. Ecol Indic 88:71-78

Merino G, Barange M, Blanchard JL, Harle J and others (2012) Can marine fisheries and aquaculture meet fish demand from a growing human population in a changing climate? Glob Environ Change 22:795-806

* Metzger R, Sartoris FJ, Langenbuch M, Pörtner HO (2007) Influence of elevated $\mathrm{CO}_{2}$ concentrations on thermal tolerance of the edible crab Cancer pagurus. J Therm Biol 32:144-151

Munday PL, McCormick MI, Nilsson GE (2012) Impact of global warming and rising $\mathrm{CO}_{2}$ levels on coral reef fishes: what hope for the future? J Exp Biol 215: 3865-3873

Nadeau M, Barbeau MA, Brêthes JC (2009) Behavioural mechanisms of sea stars (Asterias vulgaris Verrill and Leptasterias polaris Müller) and crabs (Cancer irroratus Say and Hyas araneus Linnaeus) preying on juvenile sea scallops (Placopecten magellanicus (Gmelin)), and procedural effects of scallop tethering. J Exp Mar Biol Ecol 374:134-143

Nagelkerken I, Munday PL (2016) Animal behaviour shapes the ecological effects of ocean acidification and warming: moving from individual to community-level responses. Glob Change Biol 22:974-989

Palmer AR (1990) Effect of crab effluent and scent of damaged conspecifics on feeding, growth, and shell morphology of the Atlantic dogwhelk Nucella lapillus (L.). Hydrobiologia 193:155-182

* Poloczanska ES, Brown CJ, Sydeman WJ, Kiessling W and others (2013) Global imprint of climate change on marine life. Nat Clim Change 3:919-925

Pörtner HO, Farrell AP (2008) Physiology and climate change. Science 322:690-692

* Pörtner HO, Peck MA (2010) Climate change effects on fishes and fisheries: towards a cause-and-effect understanding. J Fish Biol 77:1745-1779

R Core Team (2016) R: a language and environment for statistical computing. R Foundation for Statistical Computing, Vienna

Editorial responsibility: Gianluca Sará,

Palermo, Italy

Reviewed by: 2 anonymous referees
Reynaud S, Leclercq N, Romaine-Lioud S, Ferrier-Pagés C, Jaubert J, Gattuso JP (2003) Interacting effects of $\mathrm{CO}_{2}$ partial pressure and temperature on photosynthesis and calcification in a scleractinian coral: effects of $\mathrm{pCO}_{2}$ and temperature on coral. Glob Change Biol 9:1660-1668

* Seitz RD, Lipcius RN, Hines AH, Eggleston DB (2001) Density-dependent predation, habitat variation, and the persistence of marine bivalve prey. Ecology 82: 2435-2451

Song JP, Fang JB, Song H, Zhang T, Ban SJ, Pan Y, Li ZX (2016) Effect of feeding preferences, temperature, and size on food intake of Rapana venosa. Mark Sci 40:48-53 (in Chinese with English abstract)

Soto D, León-Muñoz J, Dresdner J, Luengo C, Tapia FJ, Garreaud R (2019) Salmon farming vulnerability to climate change in southern Chile: understanding the biophysical, socioeconomic and governance links. Rev Aquacult 11:354-374

* Sun Y, Wang F, Liu D, Dong S (2016) Behavioral mechanisms underlying the functional response of the swimming crab Portunus trituberculatus preying on the Manila clam Ruditapes philippinarum. Mar Biol 163:124

* Trussell GC, Nicklin MO (2002) Cue sensitivity, inducible defense, and trade-off in a marine snail. Ecology 83: 1635-1647

Tuomainen U, Candolin U (2011) Behavioural responses to human-induced environmental change. Biol Rev Camb Philos Soc 86:640-657

Wahl M, Saderne V, Sawall Y (2016) How good are we at assessing the impact of ocean acidification in coastal systems? Limitations, omissions and strengths of commonly used experimental approaches with special emphasis on the neglected role of fluctuations. Mar Freshw Res 67: 25-36

Waite R, Beveridge M, Brummett R, Castine S and others (2014) Improving productivity and environmental performance of aquaculture. World Resources Institute, Washington, DC

*Wong BBM, Candolin U (2015) Behavioral responses to changing environments. Behav Ecol 26:665-673

F Yang M, Song H, Yu Z, Hu Z and others (2019) The responses of digestive enzymes in juvenile and adult Rapana venosa (Valenciennes, 1846) to different temperatures. Aquacult Res 50:2846-2855

* Yu ZL, Hu N, Yang MJ, Song H and others (2019) Environmental water flow can boost foraging success of the juvenile rapa whelk Rapana venosa (Muricidae) in aquaculture tanks with still or flowing water: indication of chemosensory foraging. Aquaculture 513:734392

* Zhang T, Song H, Bai YC, Sun JC and others (2017) Effects of temperature, salinity, diet and stocking density on development of the veined Rapa whelk, Rapana venosa (Valenciennes, 1846) larvae. Aquac Int 25:1577-1590

Zippay ML, Helmuth B (2012) Effects of temperature change on mussel, Mytilus. Integr Zool 7:312-327

Submitted: August 23, 2020

Accepted: February 9, 2021

Proofs received from author(s): April 21, 2021 